\title{
Anti-Theft Box: Arduino Safety Box with IoT Notifications
}

\section{Mohamad Norul Hafiz Muzaffar Alfian' ${ }^{1}$, Athirah Nabihah Mas Erwan ${ }^{1}$, Mohamad Syafiq Mohamad Adenan ${ }^{1}$}

\author{
${ }^{1}$ Program Sains Komputer, Jabatan Komputeran. Fakulti Seni, Komputeran dan \\ Industri Kreatif. Universiti Pendidikan Sultan Idris. Tanjong Malim, Malaysia.
}

\section{Article History}

Received:

24.08.2021

Revised:

11.09.2021

Accepted:

15.09.2021

*Corresponding Author: Athirah Nabihah Mas Erwan Email:

athrhnbhhh@gmail.com

This is an open access article, licensed under: $\mathrm{CC}-\mathrm{BY}-\mathrm{SA}$
Abstract: Theft cases often go unnoticed and are everywhere we are. It can happen in public, at school, at work or even in your own home. Things like this often happen to teens and older adults. Some of them do not have a safe place to store their valuables because of their carelessness. This is because they do not take this seriously. On the other hand, they already have their own safety box which is a great example of keeping items from being stolen or robbed. With the Internet of Things (IoT), this safety box can be improved by adding features that make it even safer to receive notifications on a mobile phone when the safety box is opened. With these improvements, property owners will become more aware of their goods because not everyone around us can be trusted. The use of these notifications is an update that will be created to improve the security of your goods. The methodology used to carry out this research is called Prototyping Method. In this way, prototype can be said to be both a design and an example of an existing system, but not yet fully functional. Prototypes will outline how a system works, and most prototype systems are not yet the perfect system to run.

Keywords: Anti-Theft Box, Arduino IDE, Blynk App, Internet of Things, Thinger.Io. 


\section{Introduction}

Theft happens every year, affecting the lives of individuals around the world. Unfortunately. All these cases of theft will affect many not only the individual but also the entire community. In today's globalization of technology, one of the important things is growing for development is the Internet of Things or IoT. IoT is the current internet extension for provides communications, connections, and networks between multiple devices physical objects are also known as "Things." The IoT is the next generation or evolution. The Internet is like taking a huge leap in its ability to collect, analyze, and distribute data.

This mission can be difficult when it involves people we trust. Victims involved in these thefts can still save their goods if they increase their security to the maximum but are extremely difficult because it involves relatively expensive costs. On this site, victims will often find it difficult to find who stole because there was no camera to record their actions. If the victims were fortunate, they kept their belongings separate so that they would not be lost simultaneously but could still cause great harm on their behalf.

\section{Literatur Review}

\subsection{Internet of Things}

As the time goes by, the word "IoT" become more popular from everyone mouth and they will connect the term "IoT" with the future technology. But what is the definition of IoT, acronym for Internet of Thing? Based on the website I discovered, The internet of things, or IoT, is a system of interrelated computing devices, mechanical and digital machines, objects, animals or people that are provided with unique identifiers (UIDs) and the ability to transfer data over a network without requiring human-to-human or human-to-computer interaction [1].

IoT has evolved from the convergence of wireless technologies, microelectromechanical systems (MEMS), microservices and the internet. The convergence has helped tear down the silos between operational technologies (OT) and information technology (IT), enabling unstructured machinegenerated data to be analyzed for insights to drive improvements [2].

The first internet appliance, for example, was a Coke machine at Carnegie Mellon University in the early 1980s. Using the web, programmers could check the status of the machine and determine whether there would be a cold drink awaiting them, should they decide to make the trip to the machine [2]. Some of the related research using IoT can be seen in the Table 1.

In the modern house nowadays, the people's become more aware to install the home security system because of reliability. All these applications make IoT become a thing nowadays and will be continue and expand in the future. These days, there are many types of IoT devices that been commercialised such as Google Home Voice Controller, Amazon Echo plus Voice Controller and Kuri Mobile Robot. But all of these are the one that have been build and only for usage of that specific function. The maker culture, a culture to create their own devices need a platform that appropriate and suitable for the maker especially the developer expresses their ideas and already builtin IoT system are not suited to them.

Arduino is the best platform to learn basics of Embedded. In fact whatever an academic student has learned about sensors, led, switches and so many, this is platform on which he/she can apply their practical knowledge. A digital transformation is taking place as a consequence of recent advances of Information and Communication Technologies (ICTs). These are positively impacting in every aspect of the technological world, providing connectivity and ubiquity unimaginable few years ago. Therefore, the frontier between the physical and digital worlds is getting blurred. Such advances are generating new trends, among which the Internet of Things (IoT), Cyber-Physical Systems (CPSs), Big Data, Cloud computing, Industry 4.0 and Smart Grids (SGs) are found.

SGs are the next generation of power grids that emerge as the digital transformation applied to the energy industry. SGs are defined as a modern electric power grid infrastructure for improved efficiency, reliability, and safety with smooth integration of renewable and distributed energy sources, through automated and distributed controls and modern communication and sensing technologies.

Particularly, a Smart Micro-Grid (SMG) can be defined as a small scale SG which can be autonomous or grid-tied. SMGs integrate physical elements in the power grid and cyber elements (sensor networks, communication networks, and computation core) to make the power grid operation effective. SMGs are expected to significantly contribute to a more sustainable electricity delivery in the future decentralized paradigm of power systems [10]. 
Table 1. Research in IoT Field

\begin{tabular}{ll}
\hline \multicolumn{1}{c}{ Name } & \multicolumn{1}{c}{ Description } \\
\hline Zariman, et al [3] & $\begin{array}{l}\text { Develop a garbage monitoring using Arduino and ESP wifi that can } \\
\text { be used in the garbage management system in the city }\end{array}$ \\
\hline Azahar, et al [4] & $\begin{array}{l}\text { Develop intelligent egg incubator using Arduino Uno, PIR Sensor, } \\
\text { and ESP8266 that can be used to control the temperature of the } \\
\text { incubator }\end{array}$ \\
\hline Latif, et al [5] & $\begin{array}{l}\text { Develop smart mirror using Arduino Uno, Raspberry Pi 3, and } \\
\text { nodemcu that can be used to provide latest news updates while the } \\
\text { user do activity in front of mirror }\end{array}$ \\
\hline Husin and Hisham [6] & $\begin{array}{l}\text { Develop smart charger that can be used to control the charging time } \\
\text { to preserve battery lifetime. }\end{array}$ \\
\hline Ismail, et al [7] & $\begin{array}{l}\text { Develop smart water level indicator using Arduino Uno, Servo } \\
\text { Motor, and nodemcu ESP32 that can be used to provide early } \\
\text { warnings and control the dam of the river. }\end{array}$ \\
\hline Ghani \& Zariman [8] & $\begin{array}{l}\text { Develop smart cane to help provide safe navigation for user with } \\
\text { vision disability. }\end{array}$ \\
\hline Hermansyah, et al [9] & $\begin{array}{l}\text { Develop a remote monitoring and control system to switch main } \\
\text { energy source to backup when main source goes out. }\end{array}$ \\
\hline
\end{tabular}

\subsection{Theft Cases}

In common usage, theft is the taking of another person's property or services without that person's permission or consent with the intent to deprive the rightful owner of it. The word is also used as an informal shorthand term for some crimes against property, such as burglary, embezzlement, larceny, looting, robbery, shoplifting, library theft or fraud. In some jurisdictions, theft is considered to be synonymous with larceny; in others, theft has replaced larceny. Someone who carries out an act of or makes a career of theft is known as a thief. The act of theft is also known by other terms such as stealing, thieving, and filching. Theft is the name of a statutory offence in California, Canada, England and Wales, Hong Kong, Northern Ireland, the Republic of Ireland, and the Australian states of South Australia and Victoria.

Simple theft (also known as larceny) is a type of crime that involves unlawfully taking or using property that belongs to another person or entity. There are many different flavors of theft charges in most jurisdictions, ranging from misdemeanor shoplifting to grand theft. Typically, they all have the same basic elements (i.e., unlawfully taking property that belongs to another person or entity), but have a subtle variation, such as whether it was taken from a retail store (shoplifting), the value of what was stolen (petty or grand theft), the type of property stolen (grand theft auto), etc. Possible punishments will depend on the type of theft charges filed but some common sentences resulting from theft convictions include fines, probation, and/or jail time. Theft Cases has many types of variation, such as: identify theft, robbery, and fraud.

Identity theft charges are becoming increasingly common as personal information becomes easier to obtain. Using another person's name, bank account, credit card, or other personally identifying information without permission can result in identity theft charges being filed. This crime can be particularly damaging since in some cases, purchases made through identity theft can destroy the victim's credit score and financial resources, and by the time the theft is identified it is often too late to take much action to remedy the situation. Identity theft is now considered a federal crime in some instances, punishable by a lengthy jail sentence and forfeiture of any property bought with stolen funds. Some states also have identity theft laws [11].

Using violence, intimidation, or threats to obtain property is typically considered robbery. In other words, a robbery is a theft with the added element of the threat (or actual use) of violence. Often referred to as armed robbery or mugging, this type of charge often carries a much heavier penalty than regular larceny charges due to the use or threat of violence. While some regions have theft charges specifically for forms of robbery, other courts may file both theft and weapons or assault charges instead [12]. 
Stealing that involves deceiving someone to give up their property willingly but under false pretenses rather than using violence or simply walking away with the property is often referred to as fraud. Just as with simple theft, fraud can have many varieties based on the nature of the deception involved. For example, if someone takes property with which they were entrusted for other purposes they have committed embezzlement. If someone creates a fake currency, check, or other negotiable instrument, they may be charged with counterfeiting. If they mislead the government regarding their income, they may be guilty of tax fraud or evasion [13].

Fraud is often referred to as a "white collar" crime, as it usually involves no violence and is conducted through business dealings. Despite the use of deception rather than physical force, fraud can be extremely serious and have a devastating affect on the finances of the victim (consider those who lose their life savings in fraudulent investment schemes). Acts of fraud can result in enormous amounts of monetary and property theft, since there are often dozens, if not hundreds, of victims. As a result, sentences can vary widely, as well, from simple fines and probation to serious prison time in federal penitentiaries [13].

\subsection{Components}

There are few component that we need to gather to make this research done. The components are LCD Display, Servo Motor, Maker Uno, Keypad Membrane, Box, Node MCU V3, Jumper Wires and Ultrasonic sensor.

\subsubsection{LCD Display}

A liquid-crystal display (LCD) is a flat-panel display or other electronically modulated optical device that uses the light-modulating properties of liquid crystals combined with polarizers. Liquid crystals do not emit light directly, instead using a backlight or reflector to produce images in color or monochrome. LCDs are available to display arbitrary images (as in a general-purpose computer display) or fixed images with low information content, which can be displayed or hidden, such as preset words, digits, and seven-segment displays, as in a digital clock. They use the same basic technology, except that arbitrary images are made from a matrix of small pixels, while other displays have larger elements. LCDs can either be normally on (positive) or off (negative), depending on the polarizer arrangement. For example, a character positive LCD with a backlight will have black lettering on a background that is the color of the backlight, and a character negative LCD will have a black background with the letters being of the same color as the backlight. Optical filters are added to white on blue LCDs to give them their characteristic appearance [14].

LCDs are used in a wide range of applications, including LCD televisions, computer monitors, instrument panels, aircraft cockpit displays, and indoor and outdoor signage [14]. Small LCD screens are common in portable consumer devices such as digital cameras, watches, calculators, and mobile telephones, including smartphones. LCD screens are also used on consumer electronics products such as DVD players, video game devices and clocks. LCD screens have replaced heavy, bulky cathode ray tube (CRT) displays in nearly all applications. LCD screens are available in a wider range of screen sizes than CRT and plasma displays, with LCD screens available in sizes ranging from tiny digital watches to very large television receivers.

\subsubsection{Servo Motor}

A servomotor is a rotary actuator or linear actuator that allows for precise control of angular or linear position, velocity and acceleration [15]. It consists of a suitable motor coupled to a sensor for position feedback. It also requires a relatively sophisticated controller, often a dedicated module designed specifically for use with servomotors.

Servomotors are not a specific class of motor, although the term servomotor is often used to refer to a motor suitable for use in a closed-loop control system. Servomotors are used in applications such as robotics, $\mathrm{CNC}$ machinery or automated manufacturing.

\subsubsection{Maker Uno}

Maker UNO is an Arduino Compatible board specially designed to simplify building your researchs: coding \& Electronics made easy with built-in: $\{12 x$ LEDs; $1 x$ buzzer; $1 x$ button; $\}$. Students/Makers can skip the hassle of constructing the basic electronic circuit which is boring and time-consuming. Although it is equally important to learn about basic electronics, it can always come later after they 
have experienced how easy it is to create an awesome research. Start with fun and excitement. Start coding right away and see your board lights up and plays the melody with the press of a button [16].

\subsubsection{Keypad Membrane}

A keypad is a set of buttons arranged in a block or "pad" which bear digits, symbols or alphabetical letters. Pads mostly containing numbers are called a numeric keypad. Numeric keypads are found on alphanumeric keyboards and on other devices which require mainly numeric input such as calculators, push-button telephones, vending machines, ATMs, Point of Sale devices, combination locks, and digital door locks. Many devices follow the E.161 standard for their arrangement.

A computer keyboard usually has a small numeric keypad on the side, in addition to the other number keys on the top, but with a calculator-style arrangement of buttons that allow more efficient entry of numerical data. This number pad (commonly abbreviated to "numpad") is usually positioned on the right side of the keyboard because most people are right-handed.

The main purpose of choosing keypad for the research is to input password from the user. As this is password controlled digital safe, the user need to input the password to close the door and need to give it back to open the door back. For the research $4 \times 4$ matrix keypad is choosed over $3 \times 3$. The reason is additional A, B, C, D keys can be used to control the digital safe in different ways. Another main advantage of choosing the keypad over normal push buttons is, the user can input variety of combination of password using the keys $0-9$.

\subsubsection{Box}

Box (describes a variety of containers and receptacles for permanent use as storage, or for temporary use, often for transporting contents.

Boxes may be made of durable materials such as wood or metal, or of corrugated fiberboard, paperboard, or other non-durable materials. The size may vary from very small (e.g., a matchbox) to the size of a large appliance. A corrugated box is a very common shipping container. When no specific shape is described, a box of rectangular cross-section with all sides flat may be expected, but a box may have a horizontal cross section that is square, elongated, round or oval; sloped or domed top surfaces, or vertical edges. They are not always made up of squares.

Decorative or storage boxes may be opened by raising, pulling, sliding or removing the lid, which may be hinged and/or fastened by a catch, clasp, or lock.

\subsubsection{Node MCU V3}

NodeMCU is an open source firmware for which open source prototyping board designs are available. The name "NodeMCU" combines "node" and "MCU" (micro-controller unit). The term "NodeMCU" strictly speaking refers to the firmware rather than the associated development kits. Both the firmware and prototyping board designs are open source.

The firmware uses the Lua scripting language. It uses many open source researchs, such as luacjson and SPIFFS.Due to resource constraints, users need to select the modules relevant for their research and build a firmware tailored to their needs. Support for the 32-bit ESP32 has also been implemented.

The prototyping hardware typically used is a circuit board functioning as a dual in-line package (DIP) which integrates a USB controller with a smaller surface-mounted board containing the MCU and antenna. The choice of the DIP format allows for easy prototyping on breadboards. The design was initially was based on the ESP-12 module of the ESP8266, which is a Wi-Fi SoC integrated with a Tensilica Xtensa LX106 core, widely used in IoT applications.

\subsubsection{Ultrasonic Sensor}

Arduino IDE is a cross-platform application written in Java, and is derived from the IDE (Integrated Development Environment) for the programming language Processing and Wiring research. It is designed to introduce programming to artists and other newcomers unfamiliar with software development. This includes a code editor with features like syntax highlighting, brace matching, and automatic indentation, and is also able to compile and upload the program to the board with a single clickArduino IDE is a cross-platform application written in Java, and is derived from the IDE (Integrated Development Environment) for the programming language 
Processing and Wiring research. It is designed to introduce programming to artists and other newcomers unfamiliar with software development.

This includes a code editor with features like syntax highlighting, brace matching, and automatic indentation, and is also able to compile and upload the program to the board with a single click Arduino IDE is a cross-platform application written in Java, and is derived from the IDE (Integrated Development Environment) for the programming language Processing and Wiring research. It is designed to introduce programming to artists and other newcomers unfamiliar with software development. This includes a code editor with features like syntax highlighting, brace matching, and automatic indentation, and is also able to compile and upload the program to the board with a single click An ultrasonic sensor uses a transducer to send and receive ultrasonic pulses that relay back information about an object's proximity. High-frequency sound waves reflect from boundaries to produce distinct echo patterns. Ultrasonic sensors can detect movement of targets and measure the distance to them in many automated factories and process plants. Sensors can have an on or off digital output for detecting the movement of objects, or an analog output proportional to distance.

\subsection{Hardware Requirement}

A list of hardware requirements for developing the application is shown in Table 2.

Table 2. Hardware Requirements List

\begin{tabular}{ccl}
\hline Hardware & Specification & \multicolumn{1}{c}{ Description } \\
\hline Processor & $\begin{array}{c}\text { AMDA A6 } \\
\text { AMD dual Core A6- } \\
\text { 9225, up to 3.0 GHz }\end{array}$ & $\begin{array}{l}\text { Indicates how fast computer } \\
\text { performs certain function. }\end{array}$ \\
\hline RAM & $\begin{array}{c}\text { GB } \\
50 \mathrm{~GB}\end{array}$ & $\begin{array}{l}\text { Stores information on the } \\
\text { computer including files and } \\
\text { software programs. }\end{array}$ \\
\hline Operating System & $\begin{array}{c}\text { Microsoft Windows 10 } \\
\text { (64 bit) }\end{array}$ & $\begin{array}{l}\text { The latest operating system is the } \\
\text { requirement of many online } \\
\text { programs. }\end{array}$ \\
\hline Input Device & $\begin{array}{c}\text { Keyboard } \\
\text { Mouse }\end{array}$ & $\begin{array}{l}\text { For the input to enter the data in } \\
\text { the system. }\end{array}$ \\
\hline Arduino & Arduino Unio & $\begin{array}{l}\text { The minicomputer that has a same } \\
\text { function as a normal computer in } \\
\text { card size. }\end{array}$ \\
\hline Operating System of & Arduino IDE & $\begin{array}{l}\text { Arduino IDE is an open source } \\
\text { software that is mainly used for } \\
\text { writing and compiling the code } \\
\text { into the Arduino Module. }\end{array}$ \\
\hline
\end{tabular}

\subsection{Software Requirement}

A list of software requirements for developing the application is shown in Table 3.

Table 3. Software Requirements List

\begin{tabular}{ccl}
\hline Software & Specification & \multicolumn{1}{c}{ Description } \\
\hline $\begin{array}{c}\text { Operating System } \\
\text { of Arduino Uno }\end{array}$ & Arduino IDE & $\begin{array}{l}\text { Arduino IDE is an open source software that } \\
\text { is mainly used for writing and compiling the } \\
\text { code into the Arduino Module. It is an } \\
\text { official Arduino software fo making code } \\
\text { compilation. }\end{array}$ \\
\hline Blynk App & $\begin{array}{l}\text { IOThn is a Platform with IOS and Android } \\
\text { apps to control Arduino, Raspberry Pi and } \\
\text { and ESP8266 likes over the Internet. It's a digital } \\
\text { dashboard where you can build a graphic }\end{array}$ \\
\hline
\end{tabular}


Mohamad Norul Hafiz Muzaffar Alfian, Athirah Nabihah Mas Erwan, Mohamad Syafiq Mohamad Adenan.

\begin{tabular}{|c|c|c|}
\hline & & $\begin{array}{l}\text { interface for your research by simply } \\
\text { dragging and dropping widgets. }\end{array}$ \\
\hline Thinger.Io & $\begin{array}{l}\text { Open Source IoT } \\
\text { Platform }\end{array}$ & $\begin{array}{l}\text { Thinger.io is an Open-Source platform } \\
\text { created to simplify IoT product } \\
\text { development. The premise is quite simple, } \\
\text { use our cloud server to connect your devices } \\
\text { or create your own IoT server with the } \\
\text { Thinger.io instance, then develop and share } \\
\text { your products with a full customizable } \\
\text { graphical interface. }\end{array}$ \\
\hline
\end{tabular}

\section{Methodology}

Methodology is the systematic, theoretical analysis of the methods applies to a field of study. It comprises the theoretical analysis of the body of methods and principles associated with a branch of knowledge. Typically, it encompasses concepts such as paradigm, theoretical model, phases and quantitative or qualitative techniques. A methodology does not set out to provide solutions - it is, therefore, not the same thing as a method. Instead, it offers the theoretical underpinning for understanding which method, set of methods or best practices which can be applied to specific case.

The problem statement will help the development of the research for fulfil the requirement so that the prototype will become more function. There are many reasons why we need to choose prototype model. The reasons are Prototype model used when the desired system needs to have a lot of interaction with the end users. Secondly, Prototyping ensures that the end users constantly work with the system and provide a feedback which is incorporated in the prototype to result in a useable system. It might take a while for a system to be built that allows ease of use and needs minimal training for the end user. Build the research with several step:

STEP 1 Study well about the background of this research and IoT research. We have to understand what Iot researchs and how it's work. Prepare all the hardware requirements, software requirements and the components that used for this researchs. First of all, we need the components, then we have to download the arduino IDE software to run the arduino.

STEP 2 Test all our components either all of that working well or not. Then, we have to fix the servo motor and the ultrasonic sensor in arduino board. Then, upload the coding using the arduino IDE Software.

\section{Servo Motor:}

Red cable is connected to the $5 \mathrm{v}$ in arduino board

Brown cable is connected to the GND in arduino board

Orange cable is connected to the digital pin 7 in arduino board

Keypad membrane:

Jumper wires will connected from pin 2 to pin 10

\section{LCD display:}

GND is connected to GND

VCC is connected to $5 \mathrm{~V}$

SCL is connected to SCL

SDA is connected to SDA

\section{Ultrasonic sensor:}

VCC is connected to the $5 \mathrm{v}$ in arduino board

GND is connected to the GND in arduino board

Trigger Pin is connected to the digital pin 6 in arduino board

Echo Pin is connected to the digital pin 5 in arduino board 
STEP 3 Once done uploading the coding, the Arduino safety box will function automatically. Then, prepare the box for it make more realistic. The cover can do by ourselves using $\mathrm{x}$.

STEP 4 Download the Blynk app in our smartphone. Once done installing Blynk app, it will send the authentication code to our registered email. We have to save that authentication code.

STEP 5 Setting the NodeMCU to get the internet supply from our phone. For this, we have to fix another ultrasonic sensor to the Node MCU. So it is easy to detect the garbage level with the ultrasonic sensor and it will send the notification to the phone.

\section{Ultrasonic sensor:}

VCC is connected to the $3 \mathrm{~V} 3$ pin in Node MCU

GND is connected to the GND pin in Node MCU

Trigger Pin is connected to the $\mathrm{D} 3$ pin in Node MCU

Echo Pin is connected to the D4 pin in Node MCU

STEP 6 Upload the coding. Once done uploading the coding we have to connect our phone to the Node MCU. For this it easy to use our own mobile hotspot. Then we have to open the serial monitor to check either there are got internet connection or not.

STEP 7 Get the notifications in phone through the Blynk app.

STEP 8 Modify or design the dustbin to make sure it looks nice. We also can use any small box to keep the components.

\section{Implementation}

Implementation is the carrying out, execution, or practice of a plan, a method, or any design, idea, model, specification, standard or policy for doing something. For an implementation process to be successful, many tasks between different departments need to be accomplished in sequence. There are two types of implementation. First is hardware implementation and the second one is software implementation.

\subsection{Hardware}

Hardware implementation involves the use of the device being used. Know your device's workflow from a microcontroller for reading sensors, relay control and data transmission to the server. A hardware implementation often takes longer to create and that can make it more expensive. Prototype of the system has been shown in Figure 1.
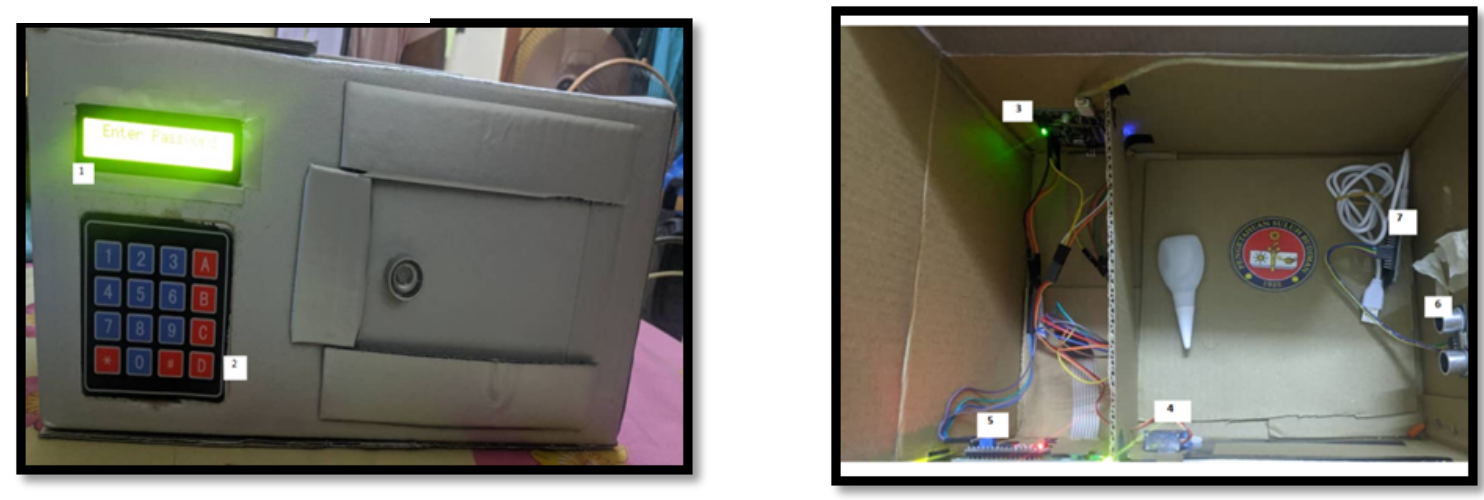

Figure 1. System Prototype 
Description:

1. Ultrasonic sensor - This sensor will helps to detect motion that trying to open the safety box.

2. Servo Motor - The servo motor has fixed at box's cover to control the door.

3. LCD Display - It will show whether you enter the right password or not.

4. Keypad Membrane - You need to enter the right password to open the door.

5. Node MCU - NodeMcu is a WiFi module that supplies the internet to the system so that Blynk app can connected to the internet and the whole research.

6. Jumper Wire - It is a conducting wire that establishes an electrical connection between two points in a circuit.

7. 9V Battery - We using 9V battery for the power supply to the arduino.

8. Powerbank - It will connected to the $9 \mathrm{~V}$ bettery and the Maker Uno and acts as power supply.

9. Maker Uno - Maker Uno is the main components that makes the sensor and the servo motor works perfectly. Arduino boards are able to read inputs such as light on a sensor, a finger on a button and turn it into an output like activating a motor, turning on an LED, publishing something online.

\subsection{Software}

Software implementation involves the use of the software being used. Software that used in this research is arduino IDE and Thiger.Io. Thinger.Io is a software that used to platform is an Open Source platform for the Internet of Things, it provides a ready to use scalable cloud infrastructure for connecting the Nodemcu. Figure below shown the coding in arduino IDE and data transmission in Thinger.Io.

\section{Coding for Arduino}

Figure 2 shows the coding used for Arduino

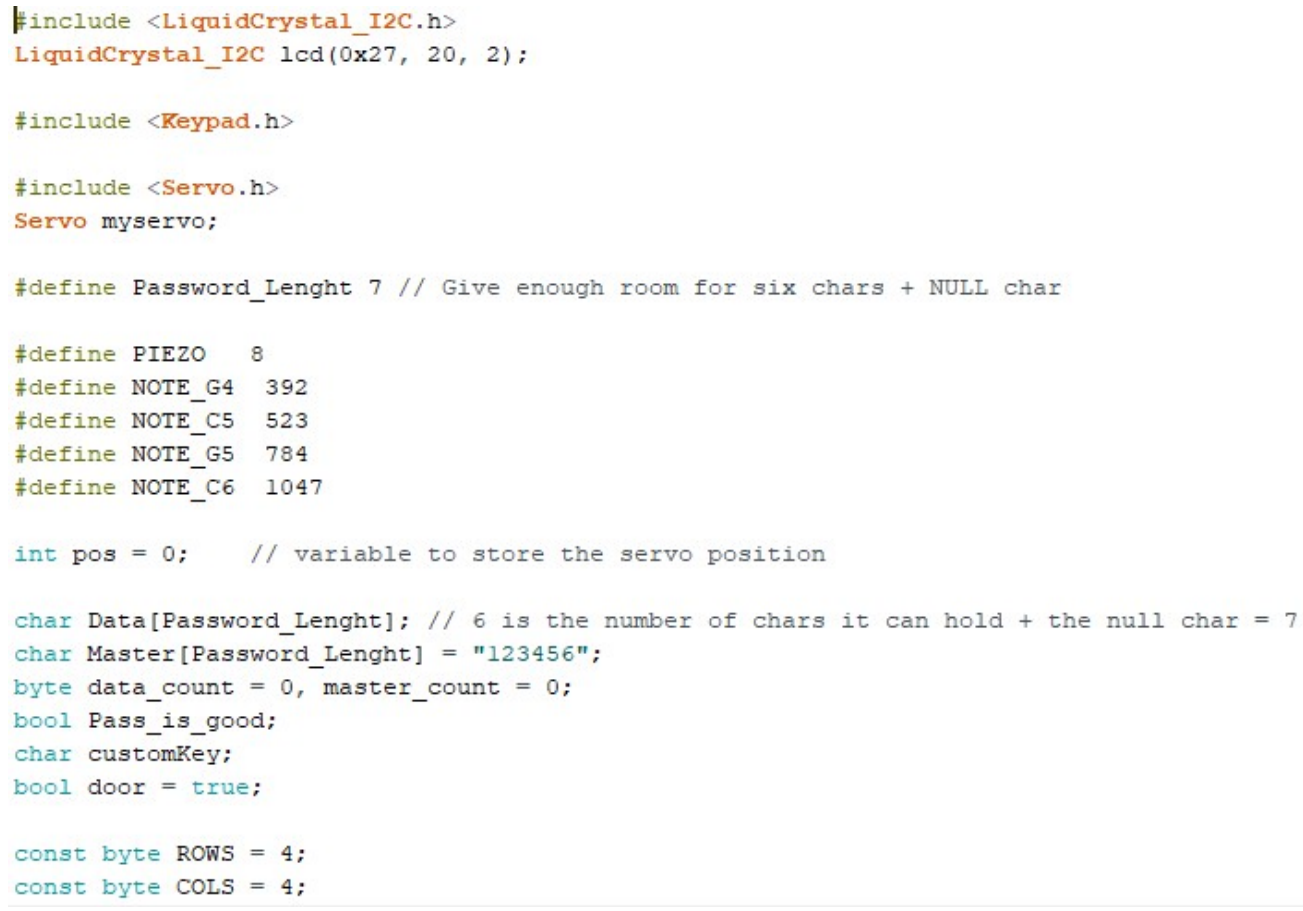

Figure 2. Coding for Arduino 
Mohamad Norul Hafiz Muzaffar Alfian, Athirah Nabihah Mas Erwan, Mohamad Syafiq Mohamad Adenan.

Anti-Theft Box: Arduino Safety Box with IoT Notifications.

International Journal of Recent Technology and Applied Science, vol 3, no. 2, pp. 67-80, September 2021. DOI: 10.36079/lamintang.ijortas-0302.000

\section{Coding for NodeMCU}

Figure 3 shows the coding used for NodeMCU

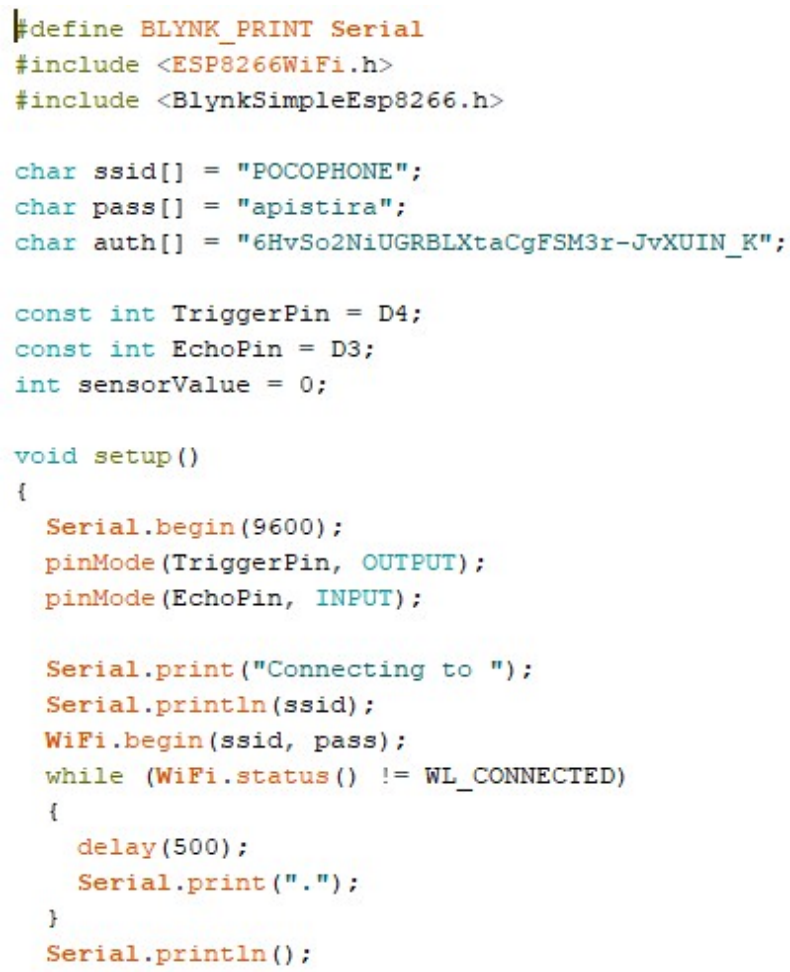

\section{Data Transmission in Thinger.Io}

Figure 4 dan Figure 5 shows the data transmission in Thinger.Io

Figure 3. Coding for NodeMCU
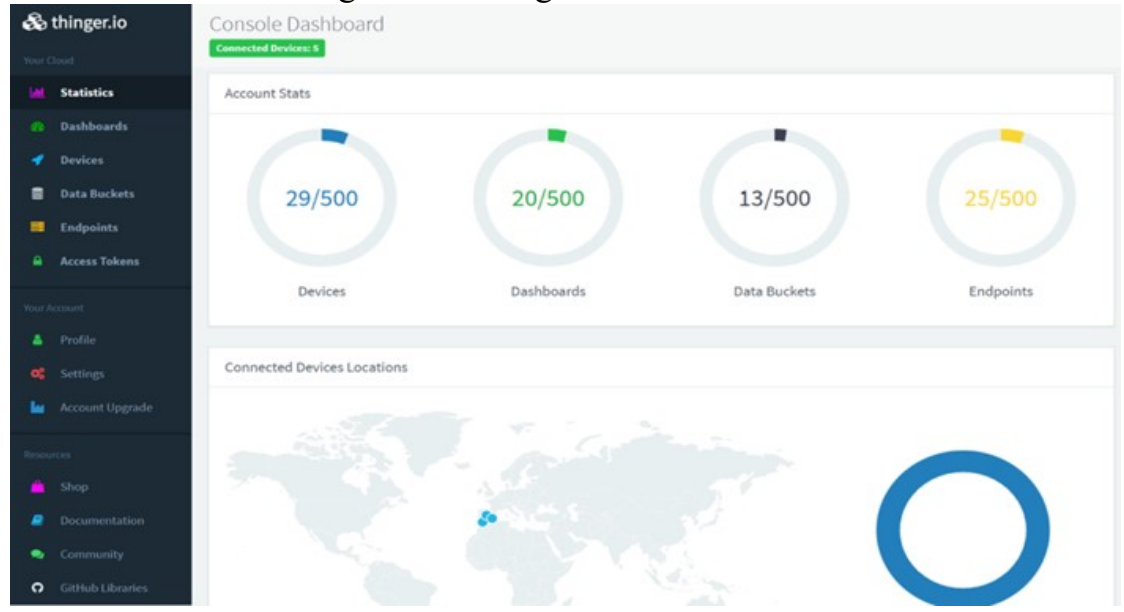

Figure 4. Data Transmission in Thinger.Io: Console Dashboard

Data Transmission shows the live transmission of Nodemcu that connected to the Blynk app here. Once you log in to your Thinger.io account, you will access by default to the Statistics section, where you can see some basic information about your account, like number of devices, endpoints, data 
buckets, endpoints and so on. There is also a map, which displays the current approximate location of your connected devices. Finally, there are some statistics about your devices consumption in terms of sent or received information.

Once the device gets connected to the account, the interface will change its status, showing that it is connected, and it is transmitting information, like in the following Figure 5.

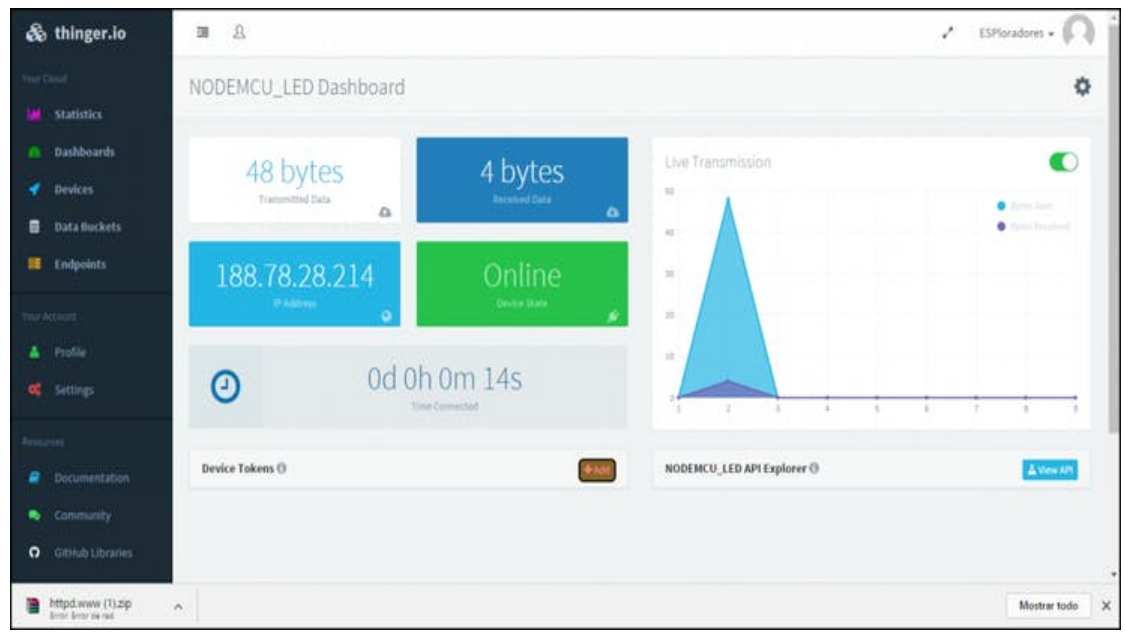

Figure 5. Data Transmission in Thinger.Io: Real Time Transmission

\subsection{Testing}

We can find out whether their code and programming work according to customer requirements. Testing is to determine whether the automated system/application software or other IT solution developed or acquired and preliminarily tested during the Development Phase is ready for implementation.

\subsubsection{Ultrasonic Sensor Motion Testing}

The ultrasonic sensor is useful for detecting objects that are some distance away. Ultrasonic sensors work by sending out a sound wave at a frequency above the range of human hearing. The sensor determines the distance to a target by measuring time lapses between the sending and receiving of the ultrasonic pulse. For calculate the distance that can detect by the ultrasonic sensor, we used measurement tape to calculate it. Table below shows the testing that done by the developer.

Table 4. Distance of Ultrasonic Sensor Detection from the Object

\begin{tabular}{ccc}
\hline $\begin{array}{c}\text { Distance from Ultrasonic } \\
\text { Sensor to the Object }\end{array}$ & Motion & $\begin{array}{c}\text { Nodemcu Receives } \\
\text { Notification }\end{array}$ \\
\hline $65 \mathrm{~cm}$ & No & No \\
\hline $60 \mathrm{~cm}$ & No & No \\
\hline $59 \mathrm{~cm}$ & No & No \\
\hline $57 \mathrm{~cm}$ & No & No \\
\hline $55 \mathrm{~cm}$ & No & No \\
\hline $45 \mathrm{~cm}$ & No & Yes \\
\hline $35 \mathrm{~cm}$ & Yes & Yes \\
\hline $25 \mathrm{~cm}$ & Yes & Yes \\
\hline $20 \mathrm{~cm}$ & Yes & Yes \\
\hline $15 \mathrm{~cm}$ & Yes & Yes \\
\hline $10 \mathrm{~cm}$ & Yes & Yes \\
\hline $5 \mathrm{~cm}$ & Yes & Yes \\
\hline $1 \mathrm{~cm}$ & Yes &
\end{tabular}




\subsubsection{Testing Based on Google. Docs Survey}

A new Google Form in order to build our survey. The new survey and edit it with others at the same time. I've created a form that will be considered as survey and once they tested my Smart Dustbin with Iot Notification research, they will fill the survey and answer the questions that provided there. Successfully, I received 35 responses from that Google. docs survey. Figure below shows the question of that this smart dustbin with Iot research's survey questions and responses of this survey.

Figure 6 shows the responses of the Arduino Safety Box research in usability testing section. It shows that 2 people stated that 3 mark, 14 people stated 4 mark and 9 people stated that 5 mark.

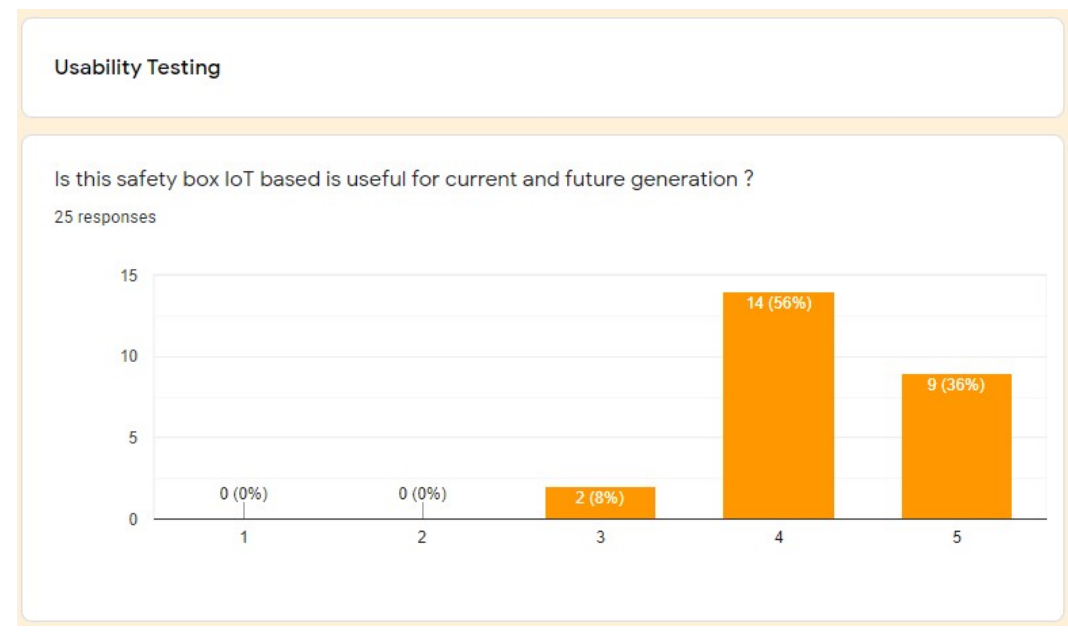

Figure 6. Responses: Useful for Current and Future

\subsection{Analysis}

Analysis is the process of breaking a complex topic or substance into smaller parts in order to gain a better understanding of it. The technique has been applied in the study of the Arduino Safety Box with Iot Notification research's. The work of literature around and then find supporting evidence in the story and research. This analysis will cover the explanation of problems and includes the solution too. Table 5 shows the analysis of that problems in this development of Arduino Box research.

Table 5. Problem and Solution in the Technical Part Error

\begin{tabular}{|c|c|c|}
\hline Problems & Solution & Technical Part \\
\hline $\begin{array}{l}\text { "SoftwareSerial } \\
\text { ESP8266" redeclared as } \\
\text { different kind of } \\
\text { symbol. }\end{array}$ & $\begin{array}{l}\text { We should install the library ESP } 8266 \text { and and } \\
\text { NodeMcu. The in the coding we should } \\
\text { declared the variable in arduino using the } \\
\text { declaration like int, char, float and so on. }\end{array}$ & $\begin{array}{l}\text { Coding in } \\
\text { Arduino }\end{array}$ \\
\hline $\begin{array}{l}\text { ESP8266_lib.h: No } \\
\text { such file or directory }\end{array}$ & $\begin{array}{l}\text { We should the install the latest version of } \\
\text { ESP8266 in Githup in google. Githup will } \\
\text { provides the latest version of library. }\end{array}$ & $\begin{array}{l}\text { Coding in } \\
\text { Arduino } \\
\text { Google githup }\end{array}$ \\
\hline $\begin{array}{l}\text { Interfacing the Blynk } \\
\text { with Node Mcu. }\end{array}$ & $\begin{array}{l}\text { In the additional Boards Manager URLS add } \\
\text { the following links provides. In the search } \\
\text { field type ESP8266. Click the ESP } 8266 \text { by } \\
\text { Eesp8266 Community. }\end{array}$ & $\begin{array}{l}\text { Coding in } \\
\text { Arduino for Node } \\
\text { Mcu. }\end{array}$ \\
\hline $\begin{array}{l}\text { BlynkSimpleEsp8266.h: } \\
\text { No such file or } \\
\text { directory }\end{array}$ & $\begin{array}{l}\text { We should installed Blynk library using built- } \\
\text { in library manager in Arduino IDE. } \\
\text { Reinstalled Blynk library as ZIP file in } \\
\text { Arduino IDE. }\end{array}$ & $\begin{array}{l}\text { Coding in } \\
\text { arduino for } \\
\text { NodeMcu }\end{array}$ \\
\hline
\end{tabular}


Mohamad Norul Hafiz Muzaffar Alfian, Athirah Nabihah Mas Erwan, Mohamad Syafiq Mohamad Adenan.

Anti-Theft Box: Arduino Safety Box with IoT Notifications.

International Journal of Recent Technology and Applied Science, vol 3, no. 2, pp. 67-80, September 2021. DOI: 10.36079/lamintang.ijortas-0302.000

\begin{tabular}{|c|c|c|}
\hline $\begin{array}{l}\text { ESP8266WiFi.h: } \\
\text { No such file or } \\
\text { directory. }\end{array}$ & $\begin{array}{l}\text { That core is used to add support to the } \\
\text { Arduino IDE for directly programming the } \\
\text { ESP8266. ESP8266WiFi.h will only be } \\
\text { accessible when you have one of the ESP8266 } \\
\text { core boards selected from the Arduino IDE's } \\
\text { Tools > Board menu. }\end{array}$ & $\begin{array}{l}\text { Coding in } \\
\text { Arduino }\end{array}$ \\
\hline $\begin{array}{l}\text { A function -definition } \\
\text { is not allowed here } \\
\text { before " }\{\text { " token. }\end{array}$ & $\begin{array}{l}\text { There's no closing "\}" for the loop() function, } \\
\text { only for the for loop in it. Once done with the } \\
\text { function code we should close that particular } \\
\text { function with "Y". }\end{array}$ & $\begin{array}{l}\text { Coding in } \\
\text { Arduino }\end{array}$ \\
\hline $\begin{array}{l}\text { 'Duration' was not } \\
\text { declared in this scope. }\end{array}$ & $\begin{array}{l}\text { It is Because int duration is initialized inside } \\
\text { the switch function. We should declare it again } \\
\text { inside the while function or outside of all of } \\
\text { the functions and make it a global function. }\end{array}$ & $\begin{array}{l}\text { Coding in } \\
\text { Arduino }\end{array}$ \\
\hline $\begin{array}{l}\text { Connection to the } \\
\text { NodeMcu and blynk } \\
\text { app in device }\end{array}$ & $\begin{array}{l}\text { For the connection, we searched in Google } \\
\text { they stated that maybe the connection is slow } \\
\text { and the data is low. So, we renewed the data } \\
\text { still not working. Then, we download the } \\
\text { flasher. Flasher is to make the connection } \\
\text { become fast. }\end{array}$ & $\begin{array}{l}\text { Coding in } \\
\text { Arduino for } \\
\text { Blynk app and } \\
\text { NodeMcu. }\end{array}$ \\
\hline $\begin{array}{l}\text { Connection to the } \\
\text { NodeMcu and blynk } \\
\text { app in device. }\end{array}$ & $\begin{array}{l}\text { The connection among the Blynk app and wifi } \\
\text { module NodeMcu quite difficult. For that } \\
\text { wechange the ssid and password. Still } \\
\text { unsuccessful. Then, I tried with my friend's } \\
\text { device. We used my friend's device as mine } \\
\text { and finaly it successful. I realized that that } \\
\text { device is the having connection Problem. So, } \\
\text { we changed the device with using my old } \\
\text { phone. }\end{array}$ & $\begin{array}{l}\text { Coding in } \\
\text { Arduino for } \\
\text { Blynk app and } \\
\text { NodeMcu. }\end{array}$ \\
\hline $\begin{array}{l}\text { Hardware components } \\
\text { designing part }\end{array}$ & $\begin{array}{l}\text { We are confused how to fix the components in } \\
\text { that Arduino Box. Then, we planned to fix all } \\
\text { the components at another box and extend all } \\
\text { the jumper wires to that box. }\end{array}$ & $\begin{array}{l}\text { Component } \\
\text { designing in } \\
\text { Smart Dustbin. }\end{array}$ \\
\hline
\end{tabular}

\section{Conclusion}

Arduino Safety Box with Iot Notification research is can hold 8 times more waste compare to normal waste bins. It houses intelligent safety sensor which stops compaction cycle when it detects hand of human being. Strengthen of Smart dustbin with IoT (Internet of Things) notification that can motion by using ultrasonic sensor. It also able to send notifications on the time when they detected a motion. This will make the residents keep them remind and easier for them to stay alert about their belongings As living standards of people are improving, safe boxes are becoming increasingly essential. A good one will save your valuables from vandalism, robberies, fire, floods, storms, earthquakes and other factors that might cause loss or damage to the things. You should consider having a trustworthy person who can access it when you are not around. Safe boxes should be installed in a secure place such as in a wall, under the furniture, in the basement, or in the flooring and secured with high-quality vaults and identification procedures.

So the conclusion of this research is we have to make sure that we need to keep our stuffs in a very comfort zone like safety box. We need to provide peace of mind to the homeowner by knowing that all the valuable items are in a protected place from unauthorized people but within his reach. This is because you don't have to stress yourself in a secure place to keep your valuables. They also save you from frustrations of tracing some official papers. The box similarly saves someone the hassle of acquiring other documents if the original ones get lost or are destroyed. It also provides peace of mind to other family members since they can access the documents with ease when authorized by the owner. And I will make some improvement to my research for the future use. Arduino safety box is 
very much important towards having your belongings safe and sound. Research has been done in employing IoT based technology in monitoring the status of safety box towards opening the box once threshold reached. It is important for every house to have a safety box. It is always advisable to own one if; you live in a high crime neighbourhood, you live in an affluent neighbourhood, you live with unattended babysitters, nannies, and maids, or you live your home unattended for several days. Get yourself one today that will assure you of your vital possessions protection.

\section{References}

[1] I. Y. Panessai, M. M. Lakulu, S. K. Subramaniam, A. F. Saad, M. I. M. Damanhuri, N. I. Yusuf, "Developing a Prototype for Sun Tracker System Based on IoT: Controlled by Mobile App and Online Database Monitoring," American Journal of Applied Sciences, vol. 16, no. 1, pp. 11-25, 2019. DOI:10.3844/ajassp.2019.11.25

[2] Yahya, Wisjhnuadji, and Arunkumar, "Automatic Safe Deposit Box Security System Using Arduino UNO," Advanced Research in Dynamical and Control Systems, vol. 9, no. 16. pp 806819, 2017.

[3] A. Zariman, M. S. Abd Latif, and A. A. Ismail, "Smart Garbage Monitoring", International Journal of Artificial Intelligence, vol. 6, no. 1, pp. 75-81, Jun. 2019.

[4] K. B. Azahar, E. E. Sekudan, and A. M. Azhar, "Intelligent Egg Incubator", International Journal of Recent Technology and Applied Science, vol. 2, no. 2, pp. 91-102, Sep. 2020.

[5] M. S. Ab Latif, A. A. Ismail, and A. Zariman, "Smart Mirror for Home Automation", International Journal of Recent Technology and Applied Science, vol. 1, no. 1, pp. 1-11, Feb. 2020.

[6] M. H. Husin, and I. D. Hisham, "Smart Charger Based on IoT Concept", International Journal of Education, Science, Technology, and Engineering, vol. 2, no. 1, pp. 39 - 44, Jun. 2019.

[7] A. A. Ismail, M. A. Azizi, and A. Zariman, "Smart Water Level Indicator", ijortas, vol. 2, no. 1, pp. 48-58, Mar. 2020.

[8] F. A. Ghani and A. Zariman, "Smart Cane based on IoT", International Journal of Education, Science, Technology, and Engineering, vol. 2, no. 1, pp. 12 - 18, Jun. 2019.

[9] Hermansyah, Kasim, and I. K. Yusri, "Solar Panel Remote Monitoring and Control System on Miniature Weather Stations Based on Web Server and ESP32", International Journal of Recent Technology and Applied Science, vol. 2, no. 1, pp. 1-24, Mar. 2020.

[10] I. Gonzalez, and A. J. Caldron, "Integration of open source hardware Arduino platform in automation systems," Sustainable Energy Technologies and Assessments, pp 100-557, 2014.

[11] K. B. Anderson, "Identify Theft," Economic Perspectives, vol. 22 no. 2, pp 171-192, 2008.

[12] L. Liu, M. Lan, and E. Eck, "Assessing the effects of bus stop relocation on street robber, Computers, Environment and Urban Systems," IJRTP, pp. 101-455, 2020.

[13] M. A. Ali, "Consumer-facing technology fraud: Economics, attack methods and potential solutions," Future Generation Computer Systems, pp. 408-427, 2019.

[14] I. Y. Panessai, M. M. Lakulu, S. K. Subramaniam, A. F. Saad, M. I. M. Damanhuri, N. I. Yusuf, "Dual axis sun tracker system based on IoT," Journal of Advanced Research in Dynamical and Control Systems, vol. 10, no. 13, pp. 2379-2394, 2018.

[15] I. D. Hashim, A. A. Ismail, and M. A. Azizi, "Solar Tracker", International Journal of Recent Technology and Applied Science, vol. 2, no. 1, pp. 59-65, Mar. 2020. 